\title{
Aplicação de manual educativo sobre a pele do recém-nascido com estudantes de
} enfermagem ${ }^{1}$

\section{Application of educative manual about skin of the newborn with students of nursing \\ Aplicación de manual educativo acerca de la piel del recién nacido con alumnos de la enfermería}

\author{
Ronald Robson Rodrigues Santos', Maria Vera Lúcia Moreira Leitão Cardoso", Grazielle Roberta \\ Freitas da Silval"I, Ingrid Martins Leite Lúcio'v
}

\begin{abstract}
RESUMO
Este estudo objetivou descrever e avaliar, na perspectiva dos alunos, a implementação de manual educativo sobre as características da pele do recém-nascido, como estratégia no processo ensino-aprendizagem da disciplina Enfermagem no Processo do Cuidar I (Criança e Adolescente). Realizado em Fortaleza, entre janeiro/junho de 2006 com 42 alunos do curso de graduação em enfermagem da UFC, que cursaram a disciplina entre 2005/2006. Para tanto foi aplicado um instrumento para avaliar a estrutura, linguagem e importância do manual para a prática de enfermagem. Destes 42 alunos, 12 se encontravam também em atividades práticas em Neonatologia, os quais responderam a outro instrumento que registrava a avaliação dos discentes acerca da contribuição do manual na sua atuação em prática com o RN. O manual foi avaliado como "satisfatório" em termos de clareza, coerência da linguagem, e conteúdo, por $100 \%$ (42) dos sujeitos. Referente à "qualidade das fotos" $90,5 \%$ (38) dos discentes o avaliou como "satisfatório" e $9,5 \%$ (4) como "não satisfatório". Os alunos que desenvolveram atividades práticas durante a pesquisa consideraram o manual como recurso facilitador para avaliar a pele do recémnascido. Conforme os resultados expostos, o manual revelou-se adequado à população alvo, assim como sua utilização para aprendizagem da temática.
\end{abstract}

Palavras chave: Enfermagem pediátrica; Recém-nascido; Pele; Ensino; Educação em enfermagem.

\section{ABSTRACT}

This study aimed to describe and evaluate, from student's perspective, the implementation of educative manual about characteristics of the skin of the newborn as strategy into process teaching-learning on course "Nursing in the Process of Care I (Child and Adolescent)". It was carried out in Fortaleza between January and June 2006 with 42 students from undergraduate Program in Nursing of UFC, who had attended that course between 2005 and 2006. For that, one instrument was applied to evaluate the manual's structure, language and importance for the nursing practice. From those 42 students, 12 also were in practice at Neonatology field which answered another instrument that registered the evaluation of the students concerning the contribution of the manual on practice with newborn. The manual was evaluated as "satisfactory" about clarity, coherence of the language, and content, by $100 \%$ (42) of the subjects. Referring the "quality of photos" $90.5 \%$ (38) of the students evaluated it as "satisfactory" and $9.5 \%$ (4) as "not satisfactory". The pupils who made practice activities during the research considered the manual as a helper resource to evaluate the skin of the newborn. According results showed, the manual revealed adequate to the target population, as well as it use for the learning of the thematic one.

\footnotetext{
${ }^{1}$ Trabalho extraído da monografia de graduação intitulada: "Aplicação de manual educativo sobre a pele do recémnascido com graduandos em enfermagem"(SANTOS, 2006). Desenvolvida no Projeto Saúde do Binômio MãeFilho/Universidade Federal do Ceará.

I Enfermeiro do Programa Saúde da Família da cidade de Morada Nova- Ceará.

"Doutora. Profa. Adjunta do Departamento de Enfermagem da FFOE/UFC. Coordenadora do Subprojeto Saúde Ocular da Criança/UFC/CNPq. Fortaleza/CE. E-mail: cardoso@ufc.br

III Enfermeira. Mestre em Enfermagem. Doutoranda do programa de Pós-graduação em Enfermagem/UFC. Integrante dos Projeto de Pesquisa Saúde do Binômio MãeFilho. Fortaleza-CE. grazielle_roberta@yahoo.com.br

IV Enfermeira. Mestre em Enfermagem. Doutoranda do programa de Pós-graduação em Enfermagem/UFC. Integrante dos Projeto de Pesquisa Saúde do Binômio MãeFilho. Fortaleza/CE. E-mail: ingrid_lucio@yahoo.com.br
} 
Key words: Pediatrics nursing; Newborn; Skin; Teaching; Education; Nursing.

\section{RESUMEN}

El estudio tuvo como objetivo describir y avaluar, en la perspectiva de los alumnos, la implementación del manual educativo sobre las características de la piel del recién nacido como estrategia en el proceso enseño-aprendizaje en la disciplina Enfermería en Proceso de Cuidar I (Niño y Adolescente). Llevado en Fortaleza entre enero y junio/2006 con 42 alumnos del curso de graduación en enfermería da UFC, que habían atendido a la disciplina entre 2005 y 2006. Para tanto, fue aplicado uno instrumento para avaluar la estructura, lengua e importancia del manual para la práctica de la enfermería. Desees 42 alumnos, 12 también se encontraban en actividades prácticas en Neonatología, los cuales responderán otro

\section{NTRODUÇÃO}

O recém-nascido (RN) não difere das crianças e adultos apenas anatomicamente. Ele apresenta particularidades anatomofisiológicas e funcionais próprias do seu período etário. Logo, o RN não é miniatura de uma criança, assim como também a criança não é a miniatura de um adulto ${ }^{(1)}$.

Tais peculiaridades devem ser conhecidas pelos enfermeiros e outros profissionais da saúde para que o neonato não seja rotulado como doente por estes e pela família. Dentre estas particularidades será destacada, neste estudo, a pele. Esta é considerada o maior órgão do ser humano e desempenha funções como proteção, percepção tátil, controle hidroeletrolítico e regulação da temperatura. Por sua vez, a incidência de dermatoses neonatais alcança $99,3 \%$, as quais são encontradas praticamente em todos os RN podendo ou não ter algum significado clínicopatológico ${ }^{(2)}$. instrumento que registraba la evaluación de los discentes acerca de la contribución del manual en su actuación en la práctica con el RN. El manual fue evaluado como "satisfactorio" en términos de la claridad, coherencia de la lengua, y contenido por $100 \%$ (42) de los sujetos. Refiriendo la "calidad de las fotos" $90.5 \%$ (38) de los alumnos lo evaluó como "satisfactorio" y $9.5 \%$ (4) como "no satisfactorio". Los alumnos que desenvolvieran actividades prácticas durante la pesquisa considerarán el manual como recurso facilitador para evaluar la piel del recién nacido. Conforme los resultados expuestos, el manual se reveló adecuado para la poblaciónalbo, así como su utilización en el aprendizaje del tema.

Palabras clave: Enfermería pediátrica; Recién nacido; Piel; Enseñanza; Educación en enfermería.

Dependendo da idade gestacional (IG), a pele do RN difere de um para o outro. A pele do RN a termo (aquele nascido entre 37 e 41 semanas de gestação) é úmida e quente ao toque, apresentando, geralmente, a lanugem protetora nos ombros e costas e uma quantidade moderada de vérnix caseoso ao nascer. A coloração da pele deste neonato é normalmente rósea, apresenta uma coloração azulada em mãos e pés, devido a uma instabilidade vasomotora, a estase capilar, e aos níveis elevados de hemoglobina. Fenômeno este conhecido por acrocianose. A pele do RN a termo (de 37 a 41 semanas inclusive) é macia, aveludada, com rugas e coberta pelo verniz caseoso ${ }^{(3)}$.

Ao contrário, a pele do RN pré-termo (aquele nascido antes de ter completado as 37 semanas de gestação) é fina, transparente, avermelhada, com lanugem protetora, pouca vérnix caseosa, e com veias visíveis, devido à escassez de tecido adiposo e a superficialidade da rede capilar ${ }^{(3)}$. Já o RN pós-termo (aquele 
Santos RRR, Cardoso MVLML, Silva GRFS, Lúcio IML. Aplicação de manual educativo sobre a pele do recém-nascido com estudantes de enfermagem. Revista Eletrônica de Enfermagem [serial on line] 2007 Set-Dez; 9(3): 759-771. Available from: URL: http://www.fen.ufg.br/revista/v9/n3/v9n3a15.htm

que nasce após 42 semanas de gestação) possui uma pele seca, inelástica, quebradiça e desprovida de lanugem e vérnix caseosa, apresentando também grande quantidade de sulcos plantares e palmares ${ }^{(4)}$.

No geral, a pele do RN apresenta-se com várias alterações ou lesões cutâneas. Essas lesões são muito variáveis, podendo ser temporárias, inocentes, resultantes de uma reação fisiológica, ou podem indicar uma alteração séria e potencialmente fatal. Algumas alterações podem surgir demonstrando graves afecções clínicas como as máculas despigmentadas em folha que é uma manifestação inicial da esclerose tuberosa, o nevo melanocístico congênito que tem grande potencial de se transformar em uma lesão maligna, as manchas café-com-leite que é com freqüência $\quad 0$ primeiro sinal da neurofibromatose ou outra afecção com envolvimento sistêmico ${ }^{(5)}$.

Por outro lado, existem lesões benignas que são bastante comuns e que não causam nenhuma preocupação do ponto de vista clínico, mas que causam medo e aflição à família, principalmente à mãe, visto que vivencia um período de instabilidade emocional e psicológica decorrente do período gestacional e do parto. Mancha mongólica, descamação fisiológica, míllium sebáceo, e eritema tóxico são exemplos dessas alterações. Por exemplo, no eritema, observa-se uma alteração autolimitada, que não requer tratamento, o que pode tranquilizar os pais ${ }^{(6)}$.

A mancha mongólica é o termo comumente utilizado para a descrição de lesões maculares benignas de tonalidade próxima ao cianótico. Variações raciais e tendência à regressão espontânea são características que a diferenciam das outras melanocitoses dérmicas. A descamação fisiológica no RN é um achado comum quando considerados os diversos graus e localizações, existem várias teorias para explicar sua etiologia, a mais aceita é que trata-se de uma perda transepidérmica de água com subseqüente desidratação do estrato córneo nos primeiros dias de vida. O míllium sebáceo é outra dermatose freqüente trata-se de pápulas brancas, peroladas, medindo entre um e $2 \mathrm{~mm}$ de diâmetro, localizadas com freqüência na face, principalmente nas regiões das bochechas, no queixo, nos sulcos nasolabiais. Já no eritema tóxico sua etiologia é desconhecida, várias hipóteses, não comprovadas, já foram aventadas, como a possibilidade de se tratar de uma diátese atópica, hipersensibilidade imediata a alérgenos ou resposta a uma estimulação térmica ou mecânica do RN ${ }^{(5-6)}$.

A importância do reconhecimento dessas lesões benignas está na orientação adequada a ser feita aos pais das crianças, que muitas vezes ficam preocupados e apreensivos por acreditarem que seus filhos apresentam alguma imperfeição ao nascimento.

Tendo em vista a freqüência dessas alterações e o trabalho do enfermeiro que interage com o paciente (mãe e filho), durante a realização de um exame físico completo no neonato, uma das atribuições deste profissional em maternidades é seu conhecimento imprescindível das dermatoses benignas bem como das demais alterações dermatológicas comumente encontradas nos RNs.

A abordagem sobre as características da pele, assim como o surgimento de lesões em recém-nascidos internados nas Unidades 
Santos RRR, Cardoso MVLML, Silva GRFS, Lúcio IML. Aplicação de manual educativo sobre a pele do recém-nascido com estudantes de enfermagem. Revista Eletrônica de Enfermagem [serial on line] 2007 Set-Dez; 9(3): 759-771. Available from: URL: http://www.fen.ufg.br/revista/v9/n3/v9n3a15.htm

Neonatais, vem sendo abordado numa perspectiva de inserir o enfermeiro no cuidado da pele do bebê ${ }^{(7)}$.

Dessa forma é fundamental ainda no contexto da formação do enfermeiro que ele tenha uma boa fundamentação teórica para a condução do exame físico do recém-nascido, de modo a detectar possíveis problemas, ou ainda ter condições de orientar a mãe com tranqüilidade a cuidar do seu bebê.

Envolvidos no desenvolvimento da disciplina Enfermagem no Processo do Cuidar I (criança e adolescente) do Curso de Graduação em Enfermagem da Faculdade de Farmácia, Odontologia e Enfermagem (FFOE) da Universidade Federal do Ceará (UFC), e vivenciando as dificuldades dos alunos diante das atividades em Neonatologia, observamos que a limitação de recursos disponíveis para o processo ensino-aprendizagem pode repercutir na origem de sentimentos, como medo e insegurança, dos alunos frente à realização do exame físico.

Nessa perspectiva, nos propusemos a confecção de um manual com o intuito deste recurso ser utilizado como instrumento educativo e conciliador das abordagens teóricopráticas da disciplina supracitada, e com isso, potencializar a atuação dos alunos neste campo de prática específico. O referido manual foi criado e organizado com fotos reais das principais alterações da pele de $\mathrm{RN}$, com revisão de literatura e cuidado de enfermagem pertinente a cada alteração.

Assim, o presente artigo tem como objetivo descrever e avaliar a implementação do uso do manual educativo sobre as características da pele do recém-nascido como estratégia facilitadora para o processo ensino- aprendizagem na disciplina Enfermagem no Processo do Cuidar I (Criança e Adolescente) e sua avaliação na perspectiva dos alunos.

\section{METODOLOGI A}

Estudo descritivo avaliativo, pois se trata de uma pesquisa onde os fatos são observados, registrados, analisados, classificados e interpretados, sem que o pesquisador interfira neles, que teve objetivo principal avaliar a utilização de uma tecnologia em educação em termos de melhoria do processo ensino-aprendizagem ${ }^{(8)}$.

Realizado na Faculdade de Farmácia, Odontologia e Enfermagem (FFOE) da Universidade Federal do Ceará (UFC), mais especificamente com alunos da graduação em enfermagem. A população foi constituída por 75 acadêmicos que cursaram a disciplina Enfermagem no Processo do Cuidar I (criança e Adolescente), tendo em vista que essa disciplina incorpora em seu conteúdo programático a temática abrangida pelo manual. O estudo foi realizado com alunos que cursaram o segundo semestre 2005 e no primeiro semestre de 2006, sendo respectivamente 40 e 35 alunos. A amostra se constituiu de 25 discentes de 2005 (amostra 1 - A1) e 17 discentes de 2006 (amostra 2 - A2) que se disponibilizaram em participar do estudo, totalizando 42 alunos.

O projeto foi apreciado e aprovado pelo Comitê de Ética em pesquisa do Complexo Hospitalar da Universidade Federal do Ceará (COMEPE), sob número de protocolo 319/05, sendo respeitadas todas as normas que regem pesquisas com seres humanos conforme a Resolução 196/96 do Conselho Nacional de Saúde. 
Todos os participantes assinaram termo de consentimento pós-esclarecido, e foram resguardadas as suas identidades reais, assim como foi permitida a saída de qualquer participante, caso desejasse, sem que houvesse prejuízo algum para o mesmo na instituição de ensino.

Os dados foram coletados entre os meses de janeiro e abril de 2006, ocasião em que ocorreu a aplicação do manual, obedecendo aos seguintes passos:

1. Os sujeitos, discentes do semestre 2005.2 foram divididos em quatro grupos de estudo com número semelhantes de componentes Os discentes do semestre 2006.1 foram divididos em três grupos de estudo com número semelhante de componentes cada. As etapas que se seguem seguiram do mesmo modo para ambas as amostras.

2. Foi entregue a cada grupo uma cópia do manual e pedido que eles o estudassem durante um período estabelecido de 30 minutos.

3. Também foi solicitado que os componentes de cada grupo discutissem cada uma das características abordadas pelo manual num intervalo de tempo préestabelecido.

Imediatamente após essa fase de aplicação do manual foi realizada a aplicação de um instrumento que buscou uma avaliação da estrutura, linguagem e importância do manual para sua prática em Neonatologia e Pediatria.

Parte dos grupos que compunham a amostra, doze alunos, seis de cada grupo, estavam realizando a prática específica em Neonatologia em respectivo campo de estágio selecionado pela disciplina. Para esses alunos fizemos ainda outro tipo de avaliação, que se baseou na aplicação de um roteiro de entrevista que visou coletar a opinião dos discentes acerca da contribuição do manual na sua atuação em campo prático, enfocando a influência do mesmo como um instrumento de suporte na prática de exame físico, especificamente na avaliação da pele do RN realizada por estes alunos.

A análise dos dados foi realizada tendo em vista as respostas dos alunos ao instrumento que previa os aspectos relativos ao recurso educativo utilizado, em termos de conteúdo, linguagem e estrutura, bem como os benefícios por eles observados e suas sugestões para melhoria do mesmo.

\section{RESULTADOS E DI SCUSSÃO}

\section{Contextualizando a disciplina e a construção do manual}

Na grade curricular (1997) do Curso de Graduação em Enfermagem da UFC a ementa da disciplina Enfermagem no Processo do Cuidar I (Criança e Adolescente) enfoca o estudo do homem desde o nascimento até a adolescência no contexto sócio-político-cultural e epidemiológico de acordo com a descrição que se segue. Perspectivas da Enfermagem Pediátrica: Condições de saúde da população infantil no Brasil; Princípios básicos de Enfermagem Pediátrica; Assistência de Enfermagem ao RN e criança sadia e/ou portadora de afecções clínicas mais freqüentes. Aplicação de metodologia da assistência de Enfermagem em Pediatria contemplando os 
Santos RRR, Cardoso MVLML, Silva GRFS, Lúcio IML. Aplicação de manual educativo sobre a pele do recém-nascido com estudantes de enfermagem. Revista Eletrônica de Enfermagem [serial on line] 2007 Set-Dez; 9(3): 759-771. Available from: URL: http://www.fen.ufg.br/revista/v9/n3/v9n3a15.htm

aspectos biológicos, psicológicos e sociais da criança e família.

O conteúdo teórico prevê o estudo dos princípios de biossegurança; da Enfermagem neonatal (características anatomofisiológicas do RN, sistema de alojamento conjunto, e cuidados de Enfermagem); aleitamento materno e alimentação complementar; assistência de enfermagem à criança portadora de doenças prevalentes na infância (infecções respiratórias agudas, diarréia e desnutrição); crescimento e desenvolvimento do lactente, todller, pré-escolar, escolar e adolescente.

A disciplina era constituída de 12 créditos correspondendo a 192horas/aula, sendo 64 horas teóricas e 128 horas práticas. As aulas teóricas eram realizadas no Departamento de Enfermagem (DENF) e as atividades práticas em seis campos de estágio, que correspondiam a espaços em que é possível, abordar os conteúdos teóricos estudados na disciplina.

Dentre os campos práticos existe um em que os alunos exercem a assistência de Enfermagem em Neonatologia, realizando vários procedimentos técnico-científicos embasados na semiologia, dentre eles está o exame físico no RN. Este, por sua vez, exige do profissional que o realiza o conhecimento de no mínimo as características anatomofisiológicas, para fundamentar a assistência de enfermagem. Em grande parte desse exame físico utilizamos a análise sistemática das condições da pele do neonato.

A motivação para a criação do manual nasceu da análise do processo de aprendizado dos alunos diante do exame físico do RN e de seus temores e dificuldades. A confecção do manual teve início com um levantamento bibliográfico aprofundado sobre as características da pele do RN, enfocando aspectos fisiológicos e patológicos. Ressaltamos que, especificamente, houve dificuldade de realização dessa etapa devido à insuficiência de referências específicas nesse assunto, no contexto da atuação da Enfermagem. Nesta etapa foram determinadas as características mais freqüentes da pele, e as que tinham maior relevância para compor o manual.

Em seguida, iniciamos o trabalho de campo o qual constou do registro das fotografias dos neonatos internados em uma instituição pública de Fortaleza. As fotografias foram registradas em máquina digital e editadas em programa específico para fotos para serem inseridas no manual. Em momento posterior, foi realizada uma triagem das mesmas levando-se em conta sua qualidade e sua relevância para compor o recurso educativo.

O momento subseqüente baseou-se na adição da revisão de literatura e intervenções/cuidados de Enfermagem pertinente a cada alteração fotografada. Destacamos que, para esse passo, foi realizada novamente a busca de literatura em livros técnico-científicos e em artigos científicos que relatassem aspectos atinentes à pele do recém-nascido, suas características normais e seus respectivos cuidados. Finalmente, realizamos a confecção do manual em si, quando ocorreu a formatação, editoração das fotos e digitação dos textos elaborados.

O resultado desse processo foi um manual contendo 21 páginas sendo descritas as seguintes características dermatológicas no RN: mancha mongólica, vérnix caseoso, lanugem protetora, míllium sebáceo, eritema 
Santos RRR, Cardoso MVLML, Silva GRFS, Lúcio IML. Aplicação de manual educativo sobre a pele do recém-nascido com estudantes de enfermagem. Revista Eletrônica de Enfermagem [serial on line] 2007 Set-Dez; 9(3): 759-771. Available from: URL: http://www.fen.ufg.br/revista/v9/n3/v9n3a15.htm

tóxico, descamação fisiológica, mancha ocular pós-credeização, icterícia neonatal, unhas e umbigo. Foram incluídos no manual análise de unhas e umbigo por também serem avaliados rotineiramente na prática do exame-fisico a essa clientela.

É oportuno dizer que todo esse processo foi realizado observando todos os aspectos éticos de pesquisa com seres humanos com autorização da instituição e da mãe do RN através de termo de consentimento pósesclarecido, que também fazia parte do projeto.

\section{A avaliação do manual na perspectiva dos}

alunos: análise do instrumento de avaliação e das entrevistas

A caracterização do grupo de alunos participantes do estudo é apresentada para podermos evidenciar aspectos relativos ao sexo e faixa etária. A amostra apresentou-se predominantemente do sexo feminino 36 $(85,7 \%)$; idade média de aproximadamente 21 anos, sendo que a idade mais freqüente foi 19 anos.

Estudo realizado por ${ }^{(9)}$ acerca do perfil dos estudantes de Enfermagem em uma Estadual do Ceará revelou que a maioria dos alunos de enfermagem era do sexo feminino (88\%), condizendo com os resultados obtidos em nosso estudo. Vale salientar que atualmente tem-se visualizado uma crescente demanda de homens na profissão, alterando um pouco o seu perfil no decorrer dos anos, apesar ainda da prevalência maior do sexo feminino ${ }^{(10)}$.

Especificando a avaliação do manual, ressaltamos as questões acerca da sua clareza e coerência conforme visualizadas no Quadro 1. Buscamos indagar a praticidade na leitura e - grau de facilidade na obtenção do conhecimento disposto no manual.

Por se tratarem de alunos de nível superior, atentamos para a permanência dos vocabulários semiotécnicos, para o aprimoramento da linguagem científica desses, cuidando para que os eufemismos e outras impropriedades fossem evitados, pois a linguagem deve ser clara, simples e direta (1112). Em benefício da clareza e objetividade, é preciso utilizar um vocábulo adequado à audiência.

Nesses aspectos, o manual recebeu de todos os participantes uma avaliação satisfatória, mostrando-se de fácil leitura e linguagem científica coerente à população a que sua aplicação foi objetivada. Portanto, consideramos que a mensagem pretendida no manual foi percebida como eficaz, como podemos verificar nos resultados da avaliação expresso na Tabela 01. 
Tabela 01: Avaliação dos alunos acerca das variáveis conteúdo, clareza, coerência e qualidades das fotos do manual, Fortaleza, 2006.

\begin{tabular}{|l|c|c|c|c|c|c|}
\hline \multirow{2}{*}{$\begin{array}{c}\text { Avaliação dos } \\
\text { alunos }\end{array}$} & \multicolumn{2}{|c|}{ Conteúdo } & \multicolumn{2}{c|}{ Clareza } & \multicolumn{2}{c|}{ Coerência } \\
\cline { 2 - 7 } & No. & $\%$ & No. & $\%$ & No. & $\%$ \\
\hline Satisfatório & 42 & 100 & 42 & 100 & 42 & 100 \\
\hline Não satisfatório & - & - & - & - & - & - \\
\hline Total & $\mathbf{4 2}$ & $\mathbf{1 0 0}$ & $\mathbf{4 2}$ & $\mathbf{1 0 0}$ & $\mathbf{4 2}$ & $\mathbf{1 0 0}$ \\
\hline
\end{tabular}

Ressaltamos ainda na Tabela 02 outro ponto no qual o manual foi analisado, o qual se refere à qualidade das fotos. Consideramos esse aspecto relevante, pois as características e qualidade das imagens contribuem sobremaneira para a visualização e percepção da mensagem do manual.

Tabela 02:. Descrição da análise da qualidade das fotos do manual, Fortaleza, 2006.

\begin{tabular}{|l|c|c|}
\hline Qualidade das Fotos & No. de respostas & \% \\
\hline Satisfatório & 38 & 90,5 \\
\hline Não Satisfatório & 4 & 9,5 \\
\hline Total & $\mathbf{4 2}$ & $\mathbf{1 0 0}$ \\
\hline
\end{tabular}

Reconhecidamente a produção do material didático constitui uma etapa crucial no processo de comunicação para a saúde. Com efeito, essa é uma tarefa que exige conhecimentos gerais e específicos, além de uma dose considerável de criatividade.

Cada vez mais é necessária a criação de novas tecnologias que impulsionem ao aluno à busca do conhecimento, pois a aprendizagem é um processo interno, que vai depender em parte da motivação do estudante para aprender, portanto, o docente deve procurar estratégias que facilitem esse processo ${ }^{(13)}$.

As ilustrações prendem mais a atenção e propicia riqueza de detalhes ao material educativo, complementando a finalidade do texto. As cores também ajudam a despertar a atenção do leitor e são fatores fundamentais para a comunicação visual gráfica $(12,14)$. Optamos pelas fotos digitalizadas reais para aproximar os alunos à sua realidade prática a posteriori, visto que esses alunos ainda não tinham contato com o RN em disciplinas anteriores dentro da grade curricular e apresentavam-se bastante ansiosos.

A análise das fotos se mostrou satisfatória para a maioria do grupo, porém uma minoria (quatro alunos) relatou a necessidade de um ajuste no foco de duas fotografias especificamente, a da descamação fisiológica e a do vérnix caseoso. Assim, ao final desse estudo, foram realizadas novamente as fotos desses dois aspectos, as quais foram incorporadas na versão final do manual. 
Santos RRR, Cardoso MVLML, Silva GRFS, Lúcio IML. Aplicação de manual educativo sobre a pele do recém-nascido com estudantes de enfermagem. Revista Eletrônica de Enfermagem [serial on line] 2007 Set-Dez; 9(3): 759-771. Available from: URL: http://www. fen.ufg. br/revista/v9/n3/v9n3a15.htm

A descamação fisiológica muitas vezes se apresenta de forma muito discreta resultante da mudança de um ambiente úmido (liquido amniótico) para um gasoso (atmosfera) ${ }^{(15)}$. No que diz respeito ao vérnix este têm como função principal a proteção do feto contra a maceração do liquido amniótico e nutrição após o parto visto que ele é rico em albumina, glicerina, vitamina $A$, colesterol, ferro entre outras substâncias. Além disso, o vérnix caseoso presente nos recém natos é absorvido pela pele em média durante 24 após o parto, o que dificultou, nesse estudo, encontrá-lo nos recém-nascidos internados no alojamento conjunto, fazendo-se necessário realizar as fotos na sala de parto, local onde foi mais facilmente visualizado, devido termos a facilidade de examinar o RN logo após o nascimento ${ }^{(3)}$.

O manual foi avaliado também em relação a sua utilidade em termos de esclarecimento e/ou complementação dos conhecimentos adquiridos em sala de aula sobre o assunto abordado. Visto que o objetivo principal de sua criação foi de servir com instrumento conciliador das abordagens teórico-práticas da disciplina Enfermagem no Processo do Cuidar I, neste ponto o mesmo também obteve unanimidade dos discentes, sendo avaliado como totalmente satisfatório nesse quesito.

Dos alunos que participaram da primeira etapa da pesquisa, doze se encontravam em campo prático da disciplina cujo conteúdo teórico abordado correspondia ao do manual. Com estes foi realizado o segundo momento da avaliação.

Nesse campo específico sobre o cuidado com o bebê, os discentes realizaram exame físico do recém-nascido e ao término dessa prática, foi entregue a eles um roteiro de entrevista que continha duas perguntas. Uma questionando a contribuição do manual para a prática da avaliação da pele do RN e outra interrogando o uso desse recurso educativo no processo de aprendizagem.

\section{Contribuição do manual para a prática de avaliação da pele do recém-nascido}

Neste tópico trabalhamos com os registros referentes a cada uma das questões separadamente e a seguir iremos tratar da primeira delas que focava na análise do aluno sobre a contribuição do manual para análise da pele do RN.

$\mathrm{Na}$ avaliação dos alunos é evidente a importância das fotos (ilustrações). Em todas as discussões essa característica do manual foi ressaltada como facilitadora do processo de aprendizagem, com pode ser observado nas respostas.

As descrições com a presença de fotos facilitaram as detecções que são necessárias no exame. (A1)

Principalmente em relação às fotos, pois permite a visualização das situações. O que contribui bastante para o aprendizado. (A1)

Contribuiu para facilitar a prática no sentido de poder visualizar melhor as características do recém-nascido através das fotos do manual. (A2)

Ele contribuiu bastante, principalmente através das ilustrações. Pois, por muitas vezes, mesmo no campo de prática, não conseguimos visualizar alguns aspectos da pele. (A2) 
Santos RRR, Cardoso MVLML, Silva GRFS, Lúcio IML. Aplicação de manual educativo sobre a pele do recém-nascido com estudantes de enfermagem. Revista Eletrônica de Enfermagem [serial on line] 2007 Set-Dez; 9(3): 759-771. Available from: URL: http://www.fen.ufg.br/revista/v9/n3/v9n3a15.htm

Explicações mais detalhadas, ilustrações que favorecem a identificação na prática. (A2)

Ajudou a identificar melhor as situações, como o manual tem fotos e descrições. (A1)

As ilustrações devem ser utilizadas não só para captar a atenção, mas também para facilitar a compreensão e a memorização da mensagem. Os desenhos, como fotos, podem direcionar melhor a mensagem ${ }^{(11-12)}$.

Sabemos ainda que a presença de imagens é muito importante no processo de educação. A imagem mental é vantajosa na resolução de problemas, e a memória é potencializada se associamos um fato a imagens correlatas ${ }^{(16)}$. Os registros abaixo ressaltam essa questão.

É um manual de busca rápida, isso facilita o nosso desempenho na prática à medida que nos familiarizamos com os termos da avaliação física da criança. E conseguirmos um bom trabalho. (A1)

Como ainda somos iniciantes na aplicação prática dos conhecimentos adquiridos em sala de aula, é comum e normal que tenhamos algumas dúvidas a respeito de algumas características do bebê. Uma vez observando as figuras e associando ao conteúdo técnico (o que o manual nos proporciona) ficamos mais preparados para atuar no hospital e lá vamos apenas fixar o que já aprendemos. (A2)

$\mathrm{Na}$ caracterização inicial da pele do RN em diferentes idades gestacionais, na detecção de anomalias patológicas relacionados a traumas, circulação ou termorregulação. (A2)
Contribuiu para sabermos que tais alterações são normais e distingui-las das patológicas. Além da identificação mais rápida. Guiou-nos muito na hora do exame físico. (A2)

Nessas falas os sujeitos focalizaram a praticidade do manual e a clareza de seu conteúdo. A mensagem deve transmitir claramente a informação e/ou orientação para que haja a compreensão de seu conteúdo, sem a possibilidade de interpretações errôneas e inadequadas ${ }^{(11)}$.

Como a escolaridade da amostra era homogênea, o uso de termos técnicos específicos da saúde não apareceu como barreira ao aprendizado. Mas, identificamos nos registros dos alunos a importância da forma direta e simples que a linguagem técnica foi aplicada.

A comunicação é sempre mais eficaz quando uma linguagem simples, direta e clara é aplicada. Assim devemos evitar a ordem inversa, frases complexas e longas, como qualquer informação não essencial para a compreensão da mensagem (11).

A segunda questão de avaliação pedia ao aluno análise da importância do uso do recurso para sua aprendizagem. De modo geral, os alunos sinalizam que o manual atendeu aos seus propósitos, facilitando o processo de análise da pele do RN e, consequentemente, a incorporação do aprendizado.

Sim, pois é um material prático com explicações breves e completas; traz figuras interessantes, etc. É importante como recurso inicial pra os alunos que vão começar a prática na instituição com os bebês. (A2) 
Santos RRR, Cardoso MVLML, Silva GRFS, Lúcio IML. Aplicação de manual educativo sobre a pele do recém-nascido com estudantes de enfermagem. Revista Eletrônica de Enfermagem [serial on line] 2007 Set-Dez; 9(3): 759-771. Available from: URL: http://www.fen.ufg.br/revista/v9/n3/v9n3a15.htm

Sim, na medida em que visualiza facilita o aprendizado e intervenções. (A1)

Com certeza, pois podemos ver de forma mais compacta os casos que mais veremos no campo de prática, sendo importante influência a presença das ilustrações. (A1)

Sim, Pois ajudou a relembrar algumas características do RN que são muitas. (A1)

Sim, pois tirou algumas dúvidas e acrescentou pontos importantes na avaliação do RN, tanto no exame físico quanto em outros procedimentos. (A2)

Sim, pois ajudou a nortear a prática através da teoria vista no manual, implementando mais o aprendizado. (A2)

Sim, só tenho uma queixa: deveria ser incluso alguns reflexos dos $\mathrm{RN}$, pelo menos os mais importantes. (A1)

Podemos identificar que as falas revelam a utilidade do manual como objeto facilitador do processo ensino-aprendizagem. A presença de ilustrações, a praticidade, clareza do manual foram os aspectos mais evidenciados pelos discentes.

Observamos também uma avaliação positiva do manual na sua utilidade em campo prático, aproximando os aspectos teóricos e práticos do processo de educação, diminuindo assim a fragmentação dicotômica do ensino.

Quando o estudante é colocado em contato direto com a realidade, é esperado que demonstre suas habilidades práticas associadas aos conhecimentos teóricos adquiridos. Esse momento tende a ser considerado pelo aluno como repleto de incertezas, ameaças e inseguranças frente às situações vivenciadas. O fato de estar em um local novo como, por exemplo, o hospital, e o encontro com uma pessoa desconhecida, o paciente, requer do aluno a habilidade para lidar não só com as suas emoções, mas também com as do outro (paciente) ${ }^{(17)}$.

$\mathrm{Na}$ última fala observamos a queixa de que, em seu conteúdo, o manual não aborda a avaliação de alguns dos reflexos primitivos presentes nos neonatos, no entanto, tal aspecto não foi incluído porque não constava dentre os objetivos propostos para a construção do manual.

Frente a isso cabe ao docente fomentar novas tecnologias e canais que melhorem a eficácia do processo educativo. Pois já não é possível conceber $o$ ensino apenas com a função de ensinar-aprender o já arquitetado pelas civilizações. Ensinar hoje, conforme a luz das tendências educacionais progressistas, anunciadas por vários autores (17-18), abrange toda uma concepção que pretende levar o aluno à conquista do já sabido, através de novas elaborações, promovendo a sua criticidade para uma ação transformadora empenhada com a realidade social ${ }^{(19)}$.

Porém, devemos tomar cuidado para que a crítica e a criatividade não sejam limitadas, e ainda permitir que as informações sejam atualizadas para evitar um distanciamento dos princípios científicos que norteiam a construção desses instrumentos que subsidiam a prática de enfermagem ${ }^{(20)}$.

Advogamos que, inserir o aluno nos processos de discussão em grupo, abordando o uso de novas tecnologias e estratégias de 
Santos RRR, Cardoso MVLML, Silva GRFS, Lúcio IML. Aplicação de manual educativo sobre a pele do recém-nascido com estudantes de enfermagem. Revista Eletrônica de Enfermagem [serial on line] 2007 Set-Dez; 9(3): 759-771. Available from: URL: http://www.fen.ufg.br/revista/v9/n3/v9n3a15.htm

ensino utilizando-se da criticidade e criatividade, favorece a implementação e eficácia do processo ensino-aprendizagem numa visão mais global e emancipatória, visto que se permite o uso do contexto coletivo.

\section{CONCLUSÕES}

Os resultados expostos mostram que o manual intitulado "a pele do recém-nascido" mostrou-se adequado à população alvo em termos de clareza e coerência de linguagem, e de conteúdo. A maioria dos participantes avaliou a qualidade das fotografias reais utilizadas como satisfatórias $(90,5 \%)$; a utilização do recurso em campo de prática foi vista como uma estratégia facilitadora para o ensino-aprendizagem na temática específica. Sendo assim, o manual referido apresenta-se como um instrumento possível de ser utilizado no contexto prático e teórico de disciplinas e estudos que abordam a pele do recém-nascido. Além disso, sugerimos que o material e método elaborado nesse estudo sejam aplicados em outro cenários/realidades, ou seja, não somente no "intra muros" da academia, mas que alce vôos e atinja os enfermeiros que lidam em sua prática com o exame físico e avaliação da pele do recém-nascido.

\section{REFERÊNCI AS}

1. Rocha RCL. História da infância: reflexões acerca de algumas concepções correntes Rev ANALECTA Guarapuava 2002; 3 (2):51-63.

2. Rivers JK, Frederiksen PC, Dibdin C. A prevalence survey of dermatoses in the Australian neonate. J Am Acad of Dermatol 1990; 23: 77-81.

3. Brêtas JRS, Quirino MD, Silva CV, Sabatés et al. Manual de exame físico para a prática da enfermagem em pediatria. Editora: IATRIA, 2005.

4. Souza ALTM, Kawamoto EE. O neonato. In: Sousa ALTM, Florio A, Kawamoto EE. (Coord.).
O neonato, a criança e o adolescente. São Paulo: E.P.U; 2001, cap.7:135-50.

5. Pereira LB, Gontijo B, Silva CMR. Dermatoses neonatais. In: CRONGRESSO BRASILEIRO DE DERMATOLOGIA 76. Rio de Janeiro; 2001. Anais Brasileiros de Dermatologia. Rio de Janeiro; 2001. CD-ROM

6. Araújo T, Schachner L. Erupções vesicopustulosas benignas no neonato. Arquivo Brasileiro Dermatologia 2006 jul-ago; 81 (4): 359-366.

7. Fontenele FC, Cardoso MVLML. Lesões de pele em recém-nascidos prematuros internados numa Unidade de Terapia Intensiva Neonatal. Rev. RENE, Fortaleza, 2005; 6(2):88-95.

8. Andrade M M. Introdução a metodologia do trabalho cientifico: elaboração de trabalhos na graduação . 3. ed. São Paulo: Atlas, 1998

9. Jorge MSB, Holanda MLT.Perfil demográfico e sócio-econômico do estudante de enfermagem da UECE. Rev. Bras. Enferm. 1996; 49 (1): 105-20.

10. Tonini, NS, Fleming SF. História de enfermagem: evolução e pesquisa. Arq. ciências saúde UNIPAR 2002 set-dez; 6(3): 131-34.

11. Ministério da Saúde (MS). Guia de produção e uso de materiais educativos 1998. Brasília, 1998

12. Silva GRF, Cardoso MVLML. Material didático para a promoção da saúde ocular da criança. Rev Paulista de Enfermagem 2007; 26(3): prelo.

13. Fernandes MGO, Barbosa VL, Naganuma M. Exame físico de enfermagem do recém-nascido a termo: software auto-instrucional. Rev. Latino-Am. Enfermagem 2006; 14 (2):243-50. 14. Ferreira OMC, Silva Júnior PD. Recursos áudio-visuais no ensino-aprendizagem. São Paulo: editora pedagógica e universitária, 1986.

15. Cunha MLC, Mendes ENW, Bolinha ALL. O cuidado com a pele do recém-nascido. Rev. gaúch. Enferm 2002; 23 (2): 6-15.

16. Thagard P. Mente: introdução à ciência cognitiva. Porto Alegre: Artmed, 1998. 210p.

17. Scherer ZAP, Scherer EA, Carvalho AMP. Reflexões sobre o ensino da enfermagem e os primeiros contatos do aluno com a profissão. Rev. Latino-Am. Enfermagem 2006; 14(2): 285-91.

18. Freire P. Educação e mudança. $20^{\mathrm{a}}$ ed. Rio de Janeiro: Paz e terra, 1994.

19. Silva JLL, Assis DL, Gentile AC. A percepção de estudantes sobre a metodologia problematizadora: a mudança de um paradigma em relação ao processo de ensinoaprendizagem. Revista Eletrônica de 
Santos RRR, Cardoso MVLML, Silva GRFS, Lúcio IML. Aplicação de manual educativo sobre a pele do recém-nascido com estudantes de enfermagem. Revista Eletrônica de Enfermagem [serial on line] 2007 Set-Dez; 9(3): 759-771. Available from: URL: http://www. fen.ufg. br/revista/v9/n3/v9n3a15. htm

Enfermagem [serial on line] 2005 Jan-Apr [cited 2006 mar 11]; 7 (1):72-80. Available from:

URL:

http://www.fen.ufg.br/revista/revista7_1/origi

nal 07. htm

20. Borges EL, Oliveira JP, Sáar SRC. Uso de manuais e instrumentos de administração na prática de enfermagem. REME - Rev.Min. Enf 2004; 8 (1): 165-252.

Artigo recebido em 23.11.06

Aprovado para publicação em 10.12.07 